\title{
Hermanos e irmãos: As relações literárias entre os românticos argentinos e brasileiros durante o romantismo
}

\section{Maria Eunice Moreira}

\begin{abstract}
Resumo: O texto analisa a troca de ideias entre escritores românticos do Brasil e da Argentina sobre a nascente história da literatura nos dois países. Tanto os argentinos conheceram os textos dos brasileiros quanto estes leram a produção dos hermanos, sobretudo no período em que a Argentina vivia sob o domínio da ditadura de Rosas, e o Brasil vivenciava os tempos áureos do Segundo Reinado. Palavras-chave: história da literatura, romantismo brasileiro, romantismo argentino.
\end{abstract}

Abstract: The text analyzes the ideas shared among Romantic writers from Brazil and Argentina on the emerging history of literature in both countries. Both Argentines and Brazilians came to know about the writing of each country, especially during the time when Argentina was ruled by the Rosas' dictatorship, and Brazil was living the golden age of the Second Empire. Keywords: history of literature, Brazilian Romanticism, Argentine Romanticism. 
Embora a historiografia literária brasileira credite aos europeus as primeiras reflexões sobre a literatura do Brasil, ressaltando as figuras do alemão Friedrich Bouterwek, do suíço Simonde de Sismondi, do francês Ferdinand Denis e do português Almeida Garrett, como as mais significativas para a formação da literatura nacional, um grupo de estudiosos de língua espanhola inseriu-se também nessa discussão. Provenientes da Europa, como Juan Valera e Adadus Calpe, ou oriundos de países da América do Sul, como Juan María Gutiérrez e José Mármol, esses intelectuais estabeleceram contato com a geração romântica brasileira e colaboraram com suas ideias para a nascente história da literatura. Tanto os argentinos conheceram os textos dos brasileiros quanto estes leram a produção dos hermanos, sobretudo no período em que a Argentina vivia sob o domínio da ditadura de Rosas, e o Brasil vivenciava os tempos áureos do Segundo Reinado. A diferença entre os regimes governamentais provocou o exílio de argentinos ao Brasil e ao Uruguai, e dessas circunstâncias desenvolveram-se, às vezes por baixo do poncho, como se diz no Sul do Brasil, fraternas relações literárias e culturais. 


\section{Es preciso moverse! ${ }^{1}$}

A América Latina começou a aparecer culturalmente ao Brasil, em 1835, por ocasião do lançamento do Bosquejo histórico, político e literário do Brasil, obra de um autor identificado apenas pelo pseudônimo - "Um Brasileiro". O patriótico cidadão era o general José Inácio de Abreu e Lima, natural do Recife, onde nascera em 1794, como filho natural do padre Roma. Sua carreira militar iniciou-se em 1812 quando se matriculou na Academia Militar no Rio de Janeiro, instituição na qual obteve a patente de capitão de artilharia. De volta ao Recife, aderiu à revolução na qual seu pai participava, foi preso e obrigado a assistir ao fuzilamento de seu progenitor. Libertado, exilou-se nos Estados Unidos, transferindo-se logo depois para a Venezuela, onde integrou o exército de Simón Bolívar e recebeu o título de general e de Libertador da Nova Granada. Em 1831, deixou a Colômbia e retornou aos Estados Unidos, mas em seguida mudou-se para a Europa, continente no qual tomou conhecimento da abdicação de d. Pedro I, a quem conheceu pessoalmente e a quem expressou sua solidariedade.

No ano seguinte, 1832, o general voltou ao Brasil, onde suas posições favoráveis à monarquia o envolveram em polêmicas e diatribes, inclusive com o jornalista Evaristo da Veiga. Foi, porém, com o objetivo de defender o Imperador que escreveu o Bosquejo histórico, político e literário do Brasil, subintitulado "Análise crítica do projeto do dr. A. F. França, oferecido em sessão de 16 de maio último à Câmara dos Deputados, reduzindo o sistema monárquico constitucional, que felizmente nos rege, a uma república democrata: seguida de outra análise do projeto do deputado Rafael de Carvalho, sobre a separação da Igreja brasileira da Santa Sé Apostólica”. A obra centra-se na formalização da denúncia do general contra o deputado baiano, dr. França, e da acusação de perjúrio, aleivosia e traição impetrada por esse deputado contra a pessoa do Imperador e das Augustas Princesas da Família Imperial. Excedendo, porém, aos propósitos políticos, transforma-se num libelo sobre a situação político-cultural do Brasil, apresentando as considerações de um arguto militar acerca das repúblicas americanas onde viveu, especialmente Estados Unidos, México e Colômbia, para comparar a situação brasileira em relação ao continente americano. Na seção final do Bosquejo, intitulada "Nosso estado intelectual", Abreu e Lima analisa o quadro cultural brasileiro e refuta qualquer possibilidade de conformação de uma vida literária no Brasil. $\mathrm{O}$ argumento que apresenta fundamenta-se na origem 
histórica do país, pois "descendentes de uma nação mesquinha em conhecimentos, pobre de ciências e de artes, não podemos elevar-nos à categoria de outros povos educados no centro de uma vasta erudição”." Tanto Portugal como o Brasil contam com alguns homens distintos pelo saber, que produziram obras de caráter geral - dicionários, memórias, ou publicações em ciências exatas ou experimentais, e até mesmo produções de caráter literário, entre as quais menciona o Caramuru, $O$ Uraguai e Marília de Dirceu - mas isso não garante a existência de um patrimônio literário nacional.

Segundo o general Abreu e Lima, o estado intelectual do Brasil é negativo: a situação brasileira não se coaduna com o estágio da ilustração dos outros povos, não satisfaz às aspirações da população nascente, e os parcos conhecimentos de alguns habitantes desaparecem no meio da imperícia do povo. A questão agrava-se quando ele afirma ainda que o país não registra um elenco de homens abalizados nas ciências de utilidade, de gosto e de ornato. A avaliação global, decorrente da observação do general, é resumida de forma negativa: "É mister confessarmos que em tudo somos medíocres e escassos".

Colocadas no cenário brasileiro da primeira metade do século xIX, as palavras do general constituíram-se em uma verdadeira "seta ervada", como ele mesmo previu, a "ferir muito amor-próprio exaltado". A seta fica mais ervada quando os argumentos contrários do autor do Bosquejo se confrontam com a posição defendida por Domingos José Gonçalves de Magalhães. Um ano depois da publicação do livro de Abreu e Lima, isto é, em 1836, o autor de Suspiros poéticos e saudades lê, em Paris, perante uma plateia de estudiosos do Instituto Histórico da França, o "Discurso sobre a história da literatura brasileira", no qual afirmava que o Brasil possuía uma literatura, apresentando como prova cabal de sua afirmativa a história dessa literatura.

Em outro ponto, a distância entre os dois textos não é apenas de ordem geográfica. Enquanto Magalhães desviava o olhar e aproximava seu país natal do continente europeu com o qual grande parte dos brasileiros desejava romper ligações, o general Abreu e Lima punha o dedo na ferida e considerava esse mesmo país no contexto cultural da América do Sul, já antecipando uma situação que seria intensificada por questões políticas.

LIMA, José Inácio de Abreu e. Bosquejo histórico, político e literário do Brasil. Niterói: Tipografia Niterói do Rego, 1835, p. 124.

3 Idem.

4 Idem 
No Brasil, o tráfego de ideias com a América espanhola, especialmente com a Argentina, acentua-se a partir da década de 1840. De lá, vinham intelectuais e políticos, que, indignados com a política de Juan Manuel de Rosas, viajavam anonimamente ao Brasil. Aqui esses homens não só aplaudiam a política do Segundo Reinado, que acolhia os estudiosos nacionais em sessões do Instituto Histórico e Geográfico Brasileiro, das quais o próprio Imperador participava e as quais presidia, como conheciam os literatos brasileiros, com eles conviviam e repartiam ideias sobre as duas literaturas em formação - a brasileira e a argentina.

Joaquim Norberto, em especial, revela-se um ponto de convergência para o fomento dessas relações literárias. Em 1844, publicou no Minerva Brasiliense, Jornal de Ciências, Letras e Artes, do Rio de Janeiro, suas "Indagações sobre a literatura argentina contemporânea", provavelmente motivado pelo "Certamen poético", realizado em Montevidéu, em 1841, quando foi discutida a literatura argentina, no movimento pós-revolucionário de 1830. Entrava em jogo, nesse Certamen, o caráter nacional que a literatura vinha tomando entre os argentinos, o que, certamente, chamou a atenção do nacionalista brasileiro.

$\mathbf{O}$ trabalho de Joaquim Norberto apresenta uma análise circunstanciada da obra poética de alguns dos primeiros autores argentinos, assumindo caráter de precursoriedade em relação aos estudiosos daquele país. Muitos anos mais tarde, na década de 1960, o crítico argentino Félix Weinberg reconheceu a posição de primazia de Norberto, ao afirmar: "[...] es un verdadero precursor pues precede a Juan María Gutiérrez y a los estudios más recientes todavía de Ricardo Rojas, sin olvidar los juicios expuestos por Marcelino Menéndez y Pelayo en su Historia de la poesía hispano americana".5

$\mathbf{O}$ artigo publicado no Minerva teve repercussão imediata. Esteban Echeverría, um intelectual argentino, em exílio no Uruguai nessa ocasião, motivado pela análise de Norberto, insistiu com seus compatriotas que passavam pelo Rio de Janeiro para buscar aproximação com o autor do artigo. Escreve Echeverría a um amigo que sairia do Rio de Janeiro em direção ao Chile:

En el n. 10 de la "Minarva (sic) brasiliense" hay un artículo sobre la literatura argentina que debe llegar a Chile y publicarlo. Hay muchos aqui que desearían ver la continuación prometida. Procure relacionarse con el autor de esse artículo y estimúlele a continuar suas indagaciones. Nos conviene mucho el juicio (que no puede ser sino imparcial) de los extran- 
jeros. Es el modo de confundir a los envidiosos y a los pandilleros. El autor de esse artículo manifiesta buen criterio literário y un conocimiento poco común, aun entre nosostros, de la literatura argentina. ${ }^{6}$

Ademais da importância da avaliação de um estrangeiro sobre a literatura argentina, que favorece a isenção crítica, Echeverría pôde vislumbrar no artigo de Norberto uma tomada de posição e uma maneira de provocar certas suscetibilidades que o quadro político em que vivia engendra. Joaquim Norberto, como se sabe, era contra os governos imperialistas, e sua visão nacionalista dominava a elaboração de seus textos, quer abordasse a literatura do Brasil quer a de outros países. Echeverría é francamente favorável à publicação do artigo do estudioso brasileiro, a ponto de para isso comprometer-se ou expor-se mais do que devia ou podia, justificando sua posição por razões que vão além das meramente literárias, como se depreende do que escreve, insistindo com a divulgação do texto de Norberto.

Si no se dice la verdad, la literatura no pode adelantar, porque el pueblo no tiene critério próprio, y ni las obras ni los talentos serán apreciados debidamente. Soy de opinión que se debe hablar sin embozo y alto cuando se trata de progreso literario y político: - Estoy resuelto a hacerlo, sufra el que sufra. De outro modo no se anda, se retrocede o se está inmoble. Haga usted y todos los amigos de Chile lo mismo, para que marchemos unidos em espiritu y en tendencias. ${ }^{7}$

Do ponto de vista literário, a crítica sobre a literatura de sua terra é verdadeira, isto é, a análise de Norberto é por ele endossável; do ponto de vista político, ela também estimula o progresso. Nada mais moderno e coerente, portanto, do que a associação entre literatura e política, na época de Norberto e de Echeverría.

Nesse mesmo tempo, escreve a Juan María Gutiérrez, outro argentino que se encontrava no Rio de Janeiro, vindo da Europa, contando-lhe a impressão que o artigo lhe havia provocado: "Contiene a más verdades que ninguno de nosotros se ha atrevido a proclamar por no herir a los que no han perdonado medio para desconceptuarnos".

Carta desde Montevideo de fecha de 24 de Diciembre de 1844, a un amigo próximo a salir para Chile del puerto de Rio de Janeiro. ECHEVERRÍA, Esteban. Obras completas. Buenos Aires: Antonio Zamora, 1951, v. 1, p. 552-3.

7 Idem

8 Idem 
Gutiérrez imediatamente procurou Joaquim Norberto para uma entrevista, forneceu-lhe materiais e informações para o segundo artigo que havia anunciado e recebeu do brasileiro um exemplar autografado de Modulações poéticas, de 1841, em que escreveu: "Ao Ilmo. Sr. D. Juan María Gutiérrez oferece o Autor". Gutiérrez anotou a lápis, abaixo da assinatura: "febrero 24 de 1845 R. de Janeiro".

Sabe-se que Norberto não publicou o segundo artigo sobre a literatura argentina, mas, por outro lado, a presença de Gutiérrez na história da literatura que o brasileiro redige é significativa, se não das relações de amizade entre os dois, pelo menos da coincidência de pensamentos entre eles. Na década de 1840, Joaquim Norberto publicou dois ensaios de historiografia literária no Minerva Brasiliense - "Estudos sobre a literatura brasileira durante o século xvir" (1843) e "Considerações gerais sobre a literatura brasileira” (1844) -, embrionários dos capítulos de sua inconclusa História da literatura brasileira que passou a publicar na Revista Popular, a partir de 1859. Dos sete capítulos publicados, quatro se referem aos escritos de Juan María Gutiérrez que não só é mencionado como fonte para sua proposta historiográfica, como textualmente comparece em citações:

Os importantes trabalhos, em que tantos ilustres literatos se hão ocupado de nossa literatura, me serviram na confecção desta história; citando muitas vezes seus belos trechos, me escudo na sua opinião mais segura e de mais critério, que por certo não é a minha. Cabe pois aqui louvar [...] entre os americanos Santiago Nunes Ribeiro, J. M. Gutiérrez e J. Mármol. ${ }^{9}$

José Mármol, mencionado por Joaquim Norberto, é também argentino e veio para o Brasil, em 1843, fugindo de Rosas, tendo fixado residência no Rio de Janeiro. A estada na capital do Império permitiu-lhe o contato com os românticos brasileiros e com os empreendimentos nacionalistas que movimentavam essa geração de intelectuais. José Mármol escreveu no Minerva Brasiliense, como registrou em carta a Gutiérrez, "Escribo también en la Minerva", datada de 13 de setembro de 1845, mas sua contribuição mais significativa encontra-se em Ostensor Brasileiro, um jornal editado por Vicente Pereira de Carvalho Guimarães e João José Moreira.

Nesse periódico, o jovem argentino encontrou espaço para publicar seus ensaios reunidos em duas séries distintas. A primeira, denominada "Fragmento da minha

SILVA, Joaquim Norberto de Sousa. Introdução histórica sobre a literatura brasileira. In: Revista Popular, Rio de Janeiro, v. 5, jan.-mar. 1860, p. 21-33. 
carteira de viagem", ${ }^{10}$ que apareceu em 1845 , esboça uma perspectiva americana, ao refletir sobre a necessidade de o fazer literário, nos novos territórios americanos, liberar-se dos preceitos europeus e ao preconizar a independência literária como corolário da autonomia política. A apresentação desses tópicos nesse primeiro conjunto de artigos amplia-se, sobretudo, nos números seguintes do Ostensor Brasileiro, para os quais Mármol contribuiu com outro feixe de artigos, sob a identificação "Juventude progressista do Rio de Janeiro"."

Nesses estudos, também adota uma perspectiva americana, enfatizando a necessidade de rompimento com os velhos padrões europeus. Para o articulista argentino, a novidade literária da América provém do romantismo, movimento que constitui a vanguarda, que traz a modernização. Segundo ele, juventude, romantismo e progresso são termos quase equivalentes, pois seus objetivos encaminham para a renovação, e é isso que pretende e exige para a América, também nova.

Disposto a realizar uma análise do papel da juventude na construção da literatura, Mármol observa ausência de diretrizes entre os literatos e, por isso, não reconhece uma literatura nacional representativa, no Brasil. A pretendida renovação literária não encontra ressonância na sociedade brasileira, cujos parâmetros são ainda muito conservadores. Segundo a sua avaliação, a sociedade está fadada ao isolamento e à esterilidade, a não ser que forças inteligentes revertam o quadro cujo diagnóstico não é favorável. Falta ao Brasil uma "efervescência social e política que acompanhe e sustente os processos de mudança literária”. ${ }^{12}$ Mármol deseja que a literatura nacional nasça da verdadeira emancipação do Brasil e almeja "exportar para os intelectuais cariocas o impulso liberador, traduzido à moda argentina", ${ }^{13}$ como diz Adriana Amante.

Escrita em 1846, no momento em que o Império brasileiro buscava sedimentar seu poder, através da instituição de mecanismos legitimadores de sua potência, principalmente alicerçados nas ideias nacionalistas dos componentes do Instituto Histórico e Geográfico Brasileiro, cujo chefe e presença marcante é o imperador Pedro II, a avaliação desse estrangeiro poderia provocar objeções por parte dos brasileiros

10 MÁRMOL, José. Fragmento de minha carteira de viagem. Ostensor Brasileiro, Rio de Janeiro, 1845. 
mais comprometidos com o processo cultural. No entanto, Mármol recebe acolhida por parte do grupo romântico. Esse assentimento pode ser medido pelo fato de que Joaquim Norberto, que havia publicado em 1841 um "Bosquejo da história da poesia brasileira", ${ }^{14}$ introdutório a Modulações poéticas, e se dedica à escrita de um livro sobre a História da literatura brasileira, recorre às ideias do amigo argentino para subsidiar seu empreendimento. A sintonia entre os dois talvez resulte do fato de que, para ambos, o quadro brasileiro apresenta deficiências, em função da feição particular que tomou o processo de emancipação da colônia em relação a Portugal, onde não houve uma ruptura violenta, possibilitando a permanência de padrões conservadores e ultrapassados.

A contribuição de José Mármol para a nascente literatura brasileira poderia ter sido mais expressiva se ele continuasse vivendo no país. No entanto, ao fim de três anos no Brasil, a saudade de sua terra e de sua gente levou-o a empreender, em abril de 1846, a viagem de retorno à pátria natal. A volta à Argentina proporciona-lhe oportunidade para estabelecer o confronto entre o cenário de sua origem e o novo, o diferente, vivido no Brasil. A comparação que decorre de sua observação permite-lhe reconhecer que, apesar dos problemas ainda evidentes na incipiente sociedade brasileira, há "uma Constituição que determina com precisão os direitos e os deveres do governo e do povo, e uma liberdade que é, sem disputa, um feito positivo e não uma teoria de escritores" ${ }^{15}$ Ao contrário do Brasil, na Argentina, onde o ordenamento político ainda é precário, a nação ressente-se de uma situação mais definida, fundamentada em instituições legais reconhecidas.

As relações literárias entre o Brasil e a Argentina voltariam novamente à cena quando, em 1856, Gonçalves de Magalhães foi alvo da severa crítica do jornalista José de Alencar sobre a epopeia A confederação dos Tamoios. Juan María Gutiérrez publicou no jornal argentino El Orden, de Buenos Aires, dois artigos sobre o autor da epopeia, comprovando, mais uma vez, que argentinos e brasileiros estavam atentos às realizações literárias de seus países. Tendo como palco a cidade do Rio de Janeiro, as cartas escritas pelo futuro autor de O guarani contra abra que deveria ser a epopeia nacional motivam uma polêmica que envolve nomes nacionais

14 SILVA, Joaquim Norberto de Sousa. Modulações poéticas. In: ZILBERMAN, Regina; MOREIRA, Maria Eunice. O berço do cânone. Textos fundadores da história da literatura brasileira. Porto Alegre: Mercado Aberto, 1998.

WEINBERG, Félix. La literatura argentina vista por un crítico brasileño en 1844. Rosario: Facultad de Filosofía y Letras, Universidade Nacional del Litoral, 1961. 
de renomada consideração, como o poeta Araújo Porto-Alegre, o venerando frei Monte Alverne e o próprio imperador d. Pedro II, que escreve para defender o poeta, seu amigo e protegido. A polêmica sobre A confederação dos Tamoios teve ampla repercussão no Brasil, mas chegou também à Argentina através do ensaio de Gutiérrez. ${ }^{16}$

Nos dias 10 e 11 de janeiro de 1857, respectivamente, nos números 429 e 430 do jornal El Orden, aparece o longo estudo crítico sobre "Um poema brasileiro - A confederação dos Tamoios, poema por Domingos Gonsalves [sic] de Magalhães. - Rio Janeiro [sic] en casa de Paula Brito, impresor de la corte. 1856: 1 v. fol. men. de 340 págs.” Sob o pseudônimo Ômega, Gutiérrez emite seu juízo sobre a epopeia brasileira e destaca os aspectos que considera positivos na construção poética de Magalhães.

Posteriormente, em 1872, esse estudo foi transcrito na Revista del Rio de la Plata e, nesse novo momento, Gutiérrez justifica as razões pelas quais inclui seu artigo na revista que está sendo lançada em Buenos Aires: “Ahora que tenemos una Revista a nuestra disposición, queremos dar nuestro nombre al presente juicio crítico que apareció bajo um seudónimo en un de los diários de Buenos Aires, hace ya algun tiempo". ${ }^{17}$ E conclui com a seguinte observação: “- Aprovechamos también esta oportunidad para corregirle, sin alterarle en lo principal, y para insertar la carta que el autor nos dirigió desde Paris, contestando a algunas de nuestras observaciones, así que llegarón a su conocimiento". ${ }^{18}$

A carta que Gutiérrez publica, 25 anos após a polêmica sobre $A$ confederação dos Tamoios, constitui a primeira - e talvez única - manifestação de Gonçalves de Magalhães sobre o poema tão combatido por José de Alencar. O texto, não datado, impede a definição de quando o poeta brasileiro escreveu essas palavras ao estudioso argentino. As hipóteses sobre esse fato podem variar, e uma delas nos leva a pensar que o passar do tempo fosse necessário para que o poeta conseguisse finalmente manifestar-se sobre o objeto da liça. Hipóteses à parte, a carta de Magalhães expressa a surpresa com que recebeu a crítica - "Grande foi a surpresa que experimentei com a leitura desta análise que revela um espírito ilustrado e reto e que tanto realce dá à

Curiosamente, no desenrolar da polêmica, no Brasil, aparece no Diário do Rio de Janeiro, de 31 de julho de 1856, um artigo assinado por Ômega, pseudônimo até hoje não desvendado. Tal coincidência entre os dois "Ômega" leva-me a conjecturar que o Ômega, que publica no jornal brasileiro, é o mesmo Ômega do jornal argentino, ou seja, Juan María Gutiérrez. de Magalhães. Revista del Rio de la Plata, Buenos Aires, n. 12, t. 3, p. 481-520, 1872.

18 Idem. 
minha obra, pois apresentada ao modo que V. o faz será mais conhecida e apreciada, única recompensa que alcançam entre nós as tarefas literárias" ${ }^{19}$-, e ressalta o sentido que atribui ao texto:

Porém indicando-me o de V. que dá maior realce à crítica, aumenta minha satisfação e não pude resistir ao veemente desejo de dirigir a Vd. a expressão de minha sincera gratidão pela honra que dispensa a meu poema, dando uma favorável notícia dele a seus compatriotas, sem que lhe movam a proceder assim as considerações de amizade. ${ }^{20}$

O parágrafo mais significativo da carta, porém, diz respeito à manifestação do poeta brasileiro sobre sua própria epopeia, escrita em 1856:

Em obras de tão longa e difícil execução, em que a imaginação não exclui o verdadeiro, senão que mais bem lhe dá esplendor, qualquer que as empreende e as realiza como melhor lhe parece, não deve ser tão vão que se julgue invulnerável à crítica, a não ser que se conte no número daqueles imortais que todas as nações consideram como nossos melhores guias na bela interpretação da natureza. Por outra parte, e do mesmo modo, tampouco a crítica de quem julga é menos falível que o gosto estético que preside àquelas composições, e não poucas vezes o que para um parece descuido ou desacerto é para outros efeito de um estudo esmerado, posto que nossos juízos e sensações variam segundo as circunstâncias, não só de indivíduo a indivíduo, senão também segundo as diversas faces de um mesmo assunto, sem que poeticamente falando sejam uns mais verdadeiros que outros. A multiplicidade e a variedade da natureza em sua própria unidade é causa do modo diferente com que se expressam os afetos, sem o qual não se conseguiria ser original na constante reprodução de uns mesmos tipos. Seria impossível a poesia se os caracteres humanos, assim como o espetáculo da natureza, ostentassem rigorosas formas geométricas. Estranha coisa é, e sem dúvida frequente, que aquelas passagens de uma obra de engenho que seu autor considera mais fracas passam quase sempre sem despertar o menor reparo, e recaia a crítica sobre pontos imprevistos e em sentido inteiramente oposto ao que pudesse presumir o autor. Tão vários são os juízos humanos! ${ }^{21}$

MAGALHÃES, Domingos José Gonçalves de. Carta a Juan María Gutiérrez. In: MOREIRA, Maria Eunice; BUENO, Luís. A confederação dos Tamoios por Domingos José Gonçalves de Magalhães. Curitiba: Editora da UFPR, 2007, p. 659. (Letras do Brasil, 7).

20 Idem.

21 Idem. 
Para Gutiérrez, o poema de Magalhães, que "pode com mais razão que seu compatriota, o autor do poema Uruguai, dizer ao seu: serás lido! Será [lido] em todas as partes", adquire um duplo valor: "não somente um poema mas uma bela ação". É por isso, por esperar que a juventude argentina se oriente pelo trabalho do brasileiro e promova a literatura pátria, que Gutiérrez estimula a leitura do original "a la generación joven de Buenos Aires que hoy se prepara a ilustrarlo en un dia próximo con las producciones de su espíritu privilegiado".22

Gutiérrez sublinha, mais uma vez, no texto de Magalhães, o aproveitamento da paisagem como elemento marcante na composição da literatura brasileira, almejando que os argentinos vislumbrem o diferencial que seja capaz de sustentar o patrimônio literário de sua terra. No entanto, ele também sabe que as condições do país não apontam para esse lado; a Argentina vive uma crise política e deve buscar outro norte para o fazer literário, que virá exatamente dessa nova conformação política. José Mármol dizia que as ideias não têm pátrias, mas essa não é a discussão que se impõe nesse momento. "As ideias não têm pátrias" pode significar, no contexto em que se inscrevem essas reflexões - a década de 1840 do século xIX; em espaços distintos e distanciados - o Brasil e a Argentina, em particular; através de homens que mantiveram fugazes e efêmeras relações - Gutiérrez passou pelo Brasil, em viagem, José Mármol permaneceu no Brasil menos de três anos e Joaquim Norberto, pelo que se sabe até hoje, nunca visitou um país da América do Sul ou sequer deixou o Rio de Janeiro -, que a circulação de ideias independe do espaço geográfico. Tanto no Brasil quanto na Argentina, nesse momento, o pensamento nacionalista transita de um lado para outro, não obstante a diferença entre as estruturas políticas e literárias vivenciadas por essas nações.

Quando a geração romântica brasileira começou a perder força, resultando no afastamento entre os hermanos e os brasileiros (Joaquim Norberto envelhecia, Mármol assumiu a Biblioteca Nacional, em Buenos Aires, antecipando com sua sina, a cegueira, a do futuro diretor, Jorge Luis Borges), parecia ter chegado ao fim a troca cultural entre as duas nações. Eis quando surge o livro de Eduardo Perié, quatro anos antes da proclamação da República brasileira, ou seja, em 1885: A literatura brasileira nos tempos coloniais - do século XVI ao começo do XIX, subintitulado "Esboço histórico seguido de uma bibliografia e trechos dos poetas e prosadores daquele período que fundaram no Brasil a cultura da língua portuguesa”. 
De rara circulação entre nós, algumas particularidades cercam essa edição: Eduardo Perié, um argentino, escreve em língua portuguesa uma história da literatura brasileira, publica-a em Buenos Aires pela Casa Editora Eduardo Perié e menciona, no texto dirigido "Ao leitor", introdutório à obra, que se trata de um trabalho "proêmio dos que com mais tempo e mais estudos [se] propõe a publicar a respeito do Brasil". Outro detalhe acrescenta-se à edição: a história da literatura de Perié compõe um volume da coleção "Biblioteca Luso-Brasileira", "cuja primeira série completa este primeiro volume", conforme esclarece. O livro é resultado de suas observações sobre o país e, mais que isso, seu lançamento se deve ao pedido de seu amigo brasileiro Félix Ferrei$\mathrm{ra},{ }^{23}$ que não só propusera o empreendimento como o auxiliara na reunião do material necessário para sua realização, escrevendo notas, indicações e algumas partes da obra.

\section{Estrangeiros e românticos}

Estranhas relações essas entre hermanos e irmãos, entre argentinos e brasileiros. Alicerçadas geralmente no silêncio, citadas com raridade e parcimônia, ocultadas por motivos políticos e ideológicos, sobretudo de lá para cá, tornam-se, porém, vozes soantes para a leitura da história da literatura de ambas as nações. Para o Brasil, o aval dos estudiosos estrangeiros, agora representado pelos intelectuais do Sul do continente, continua a tradição brasileira que os primeiros estudos historiográficos anunciaram: a persistência nas condições naturais do país, especialmente a natureza como elemento fundador da literatura nacional. A natureza tropical, vista pelos olhos desses argentinos, reforça o projeto imperial de constituição da literatura - e da nação - razão pela qual podem publicar seus "Fragmentos" nos jornais do Rio de Janeiro. $\mathrm{O}$ escritor argentino, exilado e politicamente deslocado em sua terra, era bem-vindo no Brasil onde desfrutava da posição de "viajante estrangeiro nas demandas do movimento romântico brasileiro". ${ }^{24}$

Félix Ferreira atuou como escritor, jornalista, livreiro e estudioso da arte. Colaborou na revista Cruzeiro do Brasil, do Rio de Janeiro, e na folha ilustrada O guarani. Foi autor dramático e tornou-se editor, em meados de 1877, criando a empresa Félix Ferreira \& Cia., pela qual publicou coletâneas de autores clássicos, como Luís de Camões, Diogo Bernardes, Almeida Garrett e Alexandre Herculano. Em 1885, lançou o livro Belas artes: estudos e apreciações, pela editora Baldomero Carqueja Fuentes, do Rio de Janeiro.

24 AMANTE, Adriana. O estrangeiro, muito romântico - a literatura dos escritores românticos argentinos exilados no Brasil. In: SANTOS, Luis Alberto Brandão; PEREIRA, Maria Antonieta. Trocas culturais na América Latina. Belo Horizonte: Pós-Lit/FALE/UFMG; Nelam/FALE/UFMG, 2000, p. 151-8.

Teresa revista de Literatura Brasileira [12|13]; São Paulo, p. 79-93, 2013 • 91 
Na Argentina, a metáfora de Echeverría de que o sol punha medo a seus olhos podia significar que a nascente literatura pátria, do outro lado da fronteira, tinha outro projeto e outra mirada. Entre os hermanos, a natureza não se apresentava como o signo orientador para a expressão literária. Para lá, o passado também tinha de ser encarado, como no caso do Brasil. No entanto, enquanto os brasileiros revolviam os anos anteriores à Independência em busca da tradição literária, como ensina a lição de Ferdinand Denis, para nele encontrar o produto representativo desse país solar e natural, na Argentina, do lado de lá, para usar uma expressão do escritor gaúcho Aldyr Schlee, onde a planura se impõe mais do que o sol, havia necessidade de "borrar" o passado para buscar outra construção, talvez mais voltada para a civilização do que para a barbárie.

Acentuam-se agora as diferenças entre os dois círculos culturais e literários. $\mathrm{O}$ romantismo do Brasil e o romantismo argentino movimentam-se em duas direções. No Brasil, Pedro II e sua forma de governo unificam e centralizam a pretensão de um império sólido e consistente, exercendo seu papel de mecenas sobre o grupo de intelectuais que com ele compartilham a possibilidade desse romantismo. Não há fissuras entre o grupo da nação e os literatos brasileiros que desejam promover a literatura nacional. Na Argentina, ao contrário, o romantismo deve afigurar-se com outra concepção: não há um passado que una o governo e os intelectuais, e esses almejam escrever a sua literatura em oposição ao governo central. Se, no Brasil, a literatura reforça o poder instituído, na Argentina, ao contrário, a formação dessa literatura transforma-se em elemento de contrapoder.

Hermanos e irmãos, quando discutiam a arte nacional a partir de sua condição de colonizados; hermanos e irmãos, quando entendiam que o nascimento da literatura deveria ter como berço os feitos da nação; hermanos e irmãos, quando buscavam fundar o cânone e orientar sua sedimentação pelo signo da nacionalidade. Diferentemente do Brasil, em que a política - bem ou mal - se aglutinava em torno de um chefe contrário ao confronto e de formação culta, os hermanos viveram sob a égide de caudilhos para quem, entre armas e letras, prevaleciam as primeiras e o poder da palavra era muitas vezes silenciado.

Por isso é possível entender a citação de que o sol daqui lhes punha medo. A metáfora indica que outro signo, distanciado da exuberante paisagem natural brasileira, talvez fosse mais adequado para escrever a literatura de uma pátria, que se desenhava como nação, com outras particularidades. Como disse o brasileiro mais conhecedor da literatura argentina, o crítico Joaquim Norberto, necessitam os castelhanos eleger outro motivo, mais afinado à sua realidade histórica e cultural, para então "tanger 
suas harpas". Estranhas relações e ocultas pretensões entre um grupo de homens que, muitas vezes separados pela disputa da terra ou pela ideologia de seus dirigentes, encontraram na palavra uma forma de aproximação e convivência.

Maria Eunice Moreira é professora na Pontifícia Universidade Católica (Rs) e editora da revista Letras de Hoje, do Programa de Pós-Graduação em Letras da Pontifícia Universidade Católica do Rio Grande do Sul (PUCRs); e da revista binacional Navegações - Revista de Cultura e Literaturas de Língua Portuguesa, juntamente com Vania Pinheiro (Universidade de Lisboa), desde 2007. Organizou Gonçalves Dias e a crítica portuguesa no século XIX (Portugal: Centro de Literaturas e Culturas Lusófonas e Europeias da Universidade de Lisboa, 2010) entre outros. 